\title{
Local recurrence and assessment of sentinel lymph node biopsy in deep soft tissue leiomyosarcoma of the extremities
}

\author{
Michael J Lamyman, Henk P Giele, Paul Critchley, Duncan Whitwell, Max Gibbons and Nicholas A Athanasou*
}

\begin{abstract}
Background: Leiomyosarcoma of deep soft tissues of the extremities is a rare malignant tumour treated primarily by surgery. The incidence of local recurrence and lymph node metastasis is uncertain and it is not known whether a sentinel lymph node biopsy is indicated in these tumours.

Methods: A retrospective review of patients treated for extremity deep soft tissue leiomyosarcoma at our institution over a 10-year period was conducted. Patients developing local recurrence or lymph node metastasis were identified. The presence or absence of lymphatics in the primary tumours was assessed by immunohistochemical expression of LYVE-1 and podoplanin.

Results: 27 patients (mean age 62 years) were included in the study. 15 were female and 12 male. Lymph node metastasis was seen in only two cases (7\%); intratumoural lymphatics were identified in the primary tumours of both these cases. Local recurrence occurred in $25.9 \%$ of cases despite complete excision and post-operative radiotherapy; the mean time to recurrence was 10.1 months.

Conclusion: On the basis of this study, we do not advocate sentinel lymph node biopsy in this group of patients except in those cases in which intratumoural lymphatics can be demonstrated. Close follow up is important especially for high grade leiomyosarcomas, particularly in the first year, as these tumours have a high incidence of local recurrence.
\end{abstract}

\section{Introduction}

Leiomyosarcoma of soft tissues is a malignant tumour composed of tumour cells that exhibit smooth muscle differentiation. Leiomyosarcomas are generally thought to account for $5-10 \%$ of soft tissue sarcomas [1-3]. These tumours arise most commonly in the retroperitoneum but can develop in any location; in one study of 75 soft tissue leiomyosarcomas, 33\% were noted to arise in extremity soft tissues $\backslash$ The behaviour of leiomyosarcoma of extremity deep soft tissues has not been studied independently of those arising in other locations.

Regional lymph node metastasis in patients with soft tissue sarcomas is an infrequent event occurring in 2.6 $5 \%$ of all patients [4-6]. Sentinel lymph node biopsy (SLNB) has been employed for staging of soft tissue

\footnotetext{
* Correspondence: nick.athanasou@ndorms.ox.ac.uk Nuffield Department of Orthopaedics, Rheumatology and Musculoskeltal, Sciences, University of Oxford, Department of Pathology, Nuffield Orthopaedic Centre, Oxford, OX3 7LD, UK
}

sarcomas, particularly epithelial sarcoma [7-9]. The incidence of lymph node metastasis in extremity leiomyosarcomas is clearly important with regard to whether SLNB should be carried out for this tumour. In previous retrospective reviews of the literature, pooling data from published reports on regional lymph node involvement, Weingrad and Rosenberg [10] and Mazeron and Suit [11] found the incidence in leiomyosarcoma was 10.6\% and $4 \%$ respectively; in the prospective study of Fong et al [5], the incidence was reported to be $2.7 \%$. These studies, however, did not distinguish leiomyosarcoma of extremity deep soft tissues from those arising in other locations; this is an important factor as leiomyosarcoma occurs more commonly in the retroperitoneum, mesentery, abdominal and pelvic viscera than in extremity soft tissues and lymph node metastasis from sarcomas of visceral origin occurs less commonly than from sarcomas arising in extremity soft tissues [5]. The recurrence rate following excision of deep soft tissue extremity 
leiomyosarcomas is also unknown; this has not been assessed independently of recurrence of superficial (cutaneous) leiomyosarcomas, which have a favourable prognosis, or of retroperitoneal tumours, which have a poor prognosis.

The aim of this study has been to determine the recurrence rate and incidence of lymph node metastasis of deep soft tissue leiomyosarcomas of the extremities. As the presence of lymphatic vessels has been noted in malignant soft tissue tumours that metastasise to lymph nodes [12], we determined whether immunohistochemical identification of lymphatics in the primary tumour could provide a guide as to whether lymph node metastasis of extremity leiomyosarcoma occurred and thus, whether a SLNB might be indicated in such cases.

\section{Patients and methods}

A search of the pathology database detected all patients with a histological diagnosis of deep soft tissue leiomyosarcoma over a 10 year period, between 1998 and 2008. Only patients diagnosed and treated at the Nuffield Orthopaedic Centre with leiomyosarcoma of the extremities were entered into the study. Patients with superficial cutaneous soft tissue leiomyosarcomas or gynaecological, retroperitoneal, intra-abdominal or intrathoracic primary tumours were excluded. A case notes review was performed.

Local recurrence and lymph node metastasis was considered to have occurred only if proven though open biopsy. The histological diagnosis of leiomyosarcoma was based on morphological and immunohistochemical criteria detailed in the WHO classification of soft tissue tumours [1]. Immunohistochemical expression of at least two smooth muscle antigens (smooth muscle actin, desmin, h-caldesmon) was seen in all cases. Identification of lymphatics was carried out using anti-Lyve -1 and anti-podoplanin antibodies as previously described [12].

\section{Results}

35 patients were identified as eligible for entry into the study. Five patients had to be excluded as either the case notes could not be found or were incomplete. Two patients were excluded because they died following their biopsy but before definitive surgery, and one patient was excluded because metastatic disease was found on presentation. The case notes of the remaining 27 patients were reviewed. Fifteen were female and twelve male (Figure 1). The mean age at presentation was 62 years. The mean follow up was 19.9 months, median 15 months (range 4 to 59 months). The sites of the primary tumour are shown in Figure 2. The size, grade and stage of the tumours are shown in Table 1. In all cases, local excision of the tumours was performed aiming for complete clearance with as wide a margin as possible. 21 of the patients $(78 \%)$ received adjuvant radiotherapy following primary excision. Details of patients developing local recurrence are shown in Table 2 and of those developing lymph node metastasis in Table 3. Lymph node metastasis occurred in two patients (7\%).

A review of the pathology of the primary tumour in these two cases showed that both tumours contained intratumoural lymphatics, as assessed by endothelial cell expression of the lymphatic markers, podoplanin and LYVE-1. (Figure 3) The remaining tumours, which did not metastasise to lymph nodes, were negative for lymphatic markers. In one patient the nodal recurrence was extensive, encasing femoral vessels and was not resectable. In the second patient an inguinal and iliac lymph node dissection was performed. In this patient the lymph node metastasis occurred early, before radiotherapy was instituted.

Local recurrence occurred in seven patients (25.9\%). The mean time from surgical excision to recurrence was 10.1 months (range 3-24 months). There was no incidence of local recurrence or lymph node metastasis in patients with low grade leiomyosarcoma. Post-operative radiotherapy was received by all patients who subsequently presented with local recurrence. In six of these seven patients, the tumour had been excised with a clear margin. In one patient the excision was described as marginal. In all but one case the recurrence was treated by further surgical resection.

\section{Discussion}

The role of SLNB in the management of soft tissue sarcoma has yet to be defined $[8,9,13]$. In our institution it is current practice to undertake SLNB in patients with epithelioid sarcoma given the relatively high rate of lymph node metastasis in these tumours. Previous studies have reported that the incidence of lymph node metastasis in such tumours is between 16.7 and $80 \%$ $[5,10,11]$. A positive SLNB in these cases is followed by a formal lymph node dissection. A number of soft tissue sarcomas, such as rhabdomyosarcoma, clear cell sarcoma and synovial sarcoma, have also been shown to have a propensity for regional lymph node metastasis and some observers have suggested that SLNB may be of prognostic benefit in these tumours [9]. Previous estimates of the incidence of lymph node metastasis in all patients with leiomyosarcoma have been between 2.7 and $10.6 \% .{ }^{[510 \mathrm{H}]}$ These studies examined the metastatic rate of leiomyosarcomas arising at several different sites collectively and not just that of leiomyosarcomas of deep soft tissues of the extremities. In the present study we found that the rate of lymph node metastasis in extremity deep soft tissue leiomyosarcomas to be $7 \%$. 


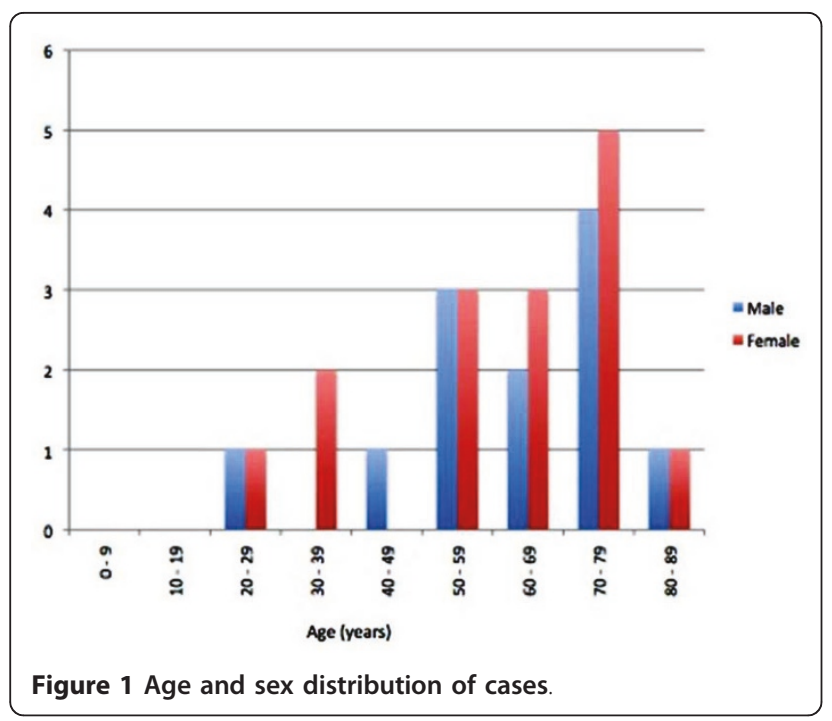

In patients with intermediate thickness melanoma, SLNB has become widely accepted as a minimally invasive method of staging the regional lymph nodes $[14,15]$. When SLNB is performed in these patients, 20\% will be found to have micrometastasis. However when SLNB is performed in thin melanomas, with a Breslow thickness less than $\mathrm{I} \mathrm{mm}$, the micrometastasis rate falls to $5 \%$ [16]. Current AJCC guidelines do not recommend routine use of SLNB in this group $[17,18]$, and on this basis the comparable rate of lymph node metastasis in deep soft tissue leiomyosarcomas would not appear to justify the extra morbidity (eg extra operating time, potential wound problems) associated with undertaking SLNB.

Recent work at our institution has shown that soft tissue sarcomas with a high propensity to metastasise to lymph nodes contain intratumoural lymphatics [12]; intratumoural lymphatics were found to be present in all epithelioid sarcomas and a number of other sarcomas including leiomyosarcoma. Lymph node metastasis has been reported in up to $80 \%$ of epithelioid sarcomas $[5,10,11]$. The lower incidence of lymph node metastasis in leiomyosarcomas may reflect the fact that intratumoural lymphatics are found less commonly in these tumours. It is none the less significant that in our study the two leiomyoarcomas which did metastasise to regional lymph nodes both contained intratumoural lymphatics. Immunohistochemical demonstration of lymphatic vessels in these primary leiomysarcomas was of prognostic significance with regard to the development of lymph node metastasis, and it could be argued that SLNB is indicated in primary leiomyosarcomas of the extremities where intratumoural lymphatics are identified.

We found a high rate of local recurrence in extremity deep soft tissue leiomyosarcoma patients with $25.9 \%$ experiencing recurrence despite adequate resection and adjuvant radiotherapy. Mankin and Hornicek report a recurrence rate of $10.8 \%$ in 65 patients with leiomyosarcoma [19]. Again this study did not differentiate between leiomyosarcoma of the extremities and other

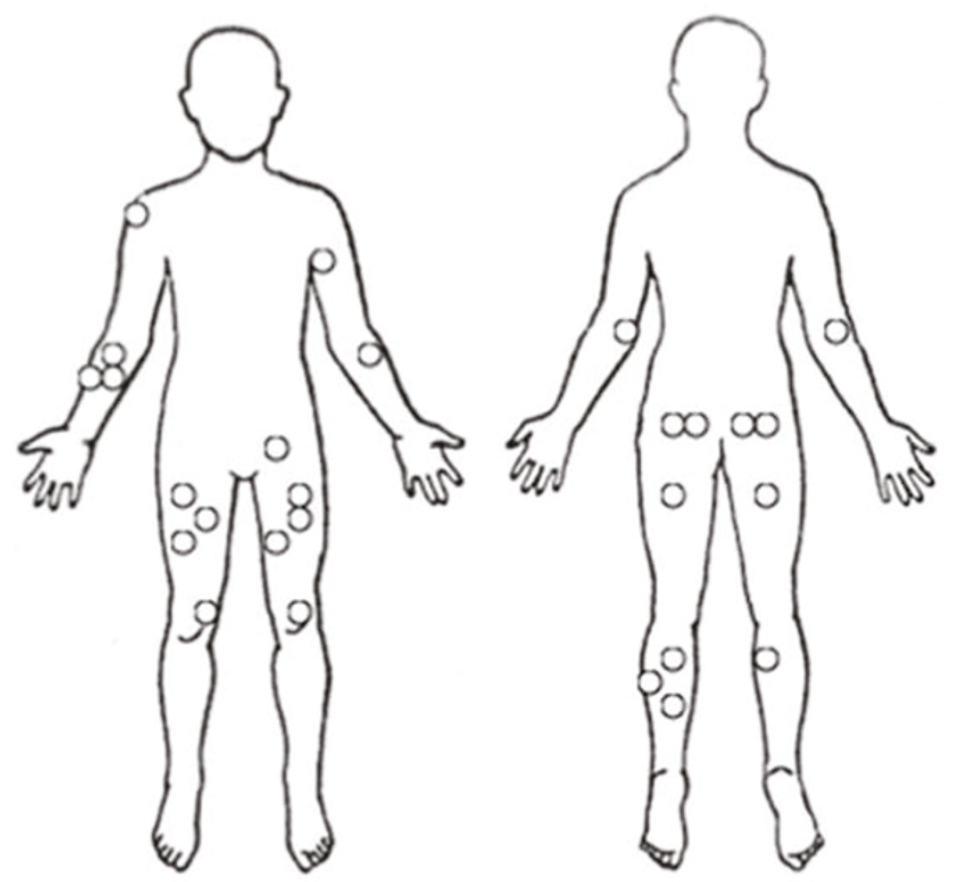

$\begin{array}{lll}\text { Thigh } & 8 & (29 \%) \\ \text { Buttock } & 4 & (15 \%) \\ \text { Calf } & 4 & (15 \%) \\ \text { Forearm } & 4 & (15 \%) \\ \text { Knee } & 2 & (7 \%) \\ \text { Elbow } & 2 & (7 \%) \\ \text { Groin } & 1 & (4 \%) \\ \text { Shoulder } & 1 & (4 \%) \\ \text { Arm } & 1 & (4 \%)\end{array}$

Figure 2 Sites of primary tumour with number and approximate percentage of cases. 
Table 1 Size, Grade and Stage of the primary leiomyosarcoma

\begin{tabular}{|c|c|c|c|}
\hline Case & Size in maximum Diameter $(\mathrm{cm})$ & Grade & MSTS Stage \\
\hline 1 & 18 & 2 & $2 b$ \\
\hline 2 & 8 & 3 & $2 b$ \\
\hline 3 & 5 & 3 & $2 b$ \\
\hline 4 & Unknown & 2 & $2 b$ \\
\hline 5 & 7.5 & 1 & $\mathrm{lb}$ \\
\hline 6 & 4.5 & 2 & $\mathrm{lb}$ \\
\hline 7 & 10 & 3 & $2 b$ \\
\hline$S$ & 7 & 3 & $2 b$ \\
\hline 9 & 4 & 2 & $2 b$ \\
\hline 10 & 8 & 3 & $2 b$ \\
\hline 11 & 13 & 3 & $2 b$ \\
\hline 12 & 14 & 3 & $2 b$ \\
\hline 13 & 2 & 2 & $2 b$ \\
\hline 14 & 3.8 & 1 & $\mathrm{lb}$ \\
\hline 15 & 12 & 2 & $2 b$ \\
\hline 16 & 25 & 2 & $2 b$ \\
\hline 17 & 12 & 2 & $2 b$ \\
\hline 18 & 3.5 & 2 & $2 b$ \\
\hline 19 & 8.5 & 3 & $2 b$ \\
\hline 20 & 10 & 3 & $2 b$ \\
\hline 21 & 16 & 3 & $2 b$ \\
\hline 22 & 9 & 1 & lb \\
\hline 23 & 13 & 1 & $\mathrm{lb}$ \\
\hline 24 & 9 & 3 & 3 \\
\hline 25 & Unknown & 2 & $2 b$ \\
\hline 26 & 10 & 3 & $2 b$ \\
\hline 27 & 8 & 3 & $2 b$ \\
\hline
\end{tabular}

MSTS - Musculoskeletal Tumour Society

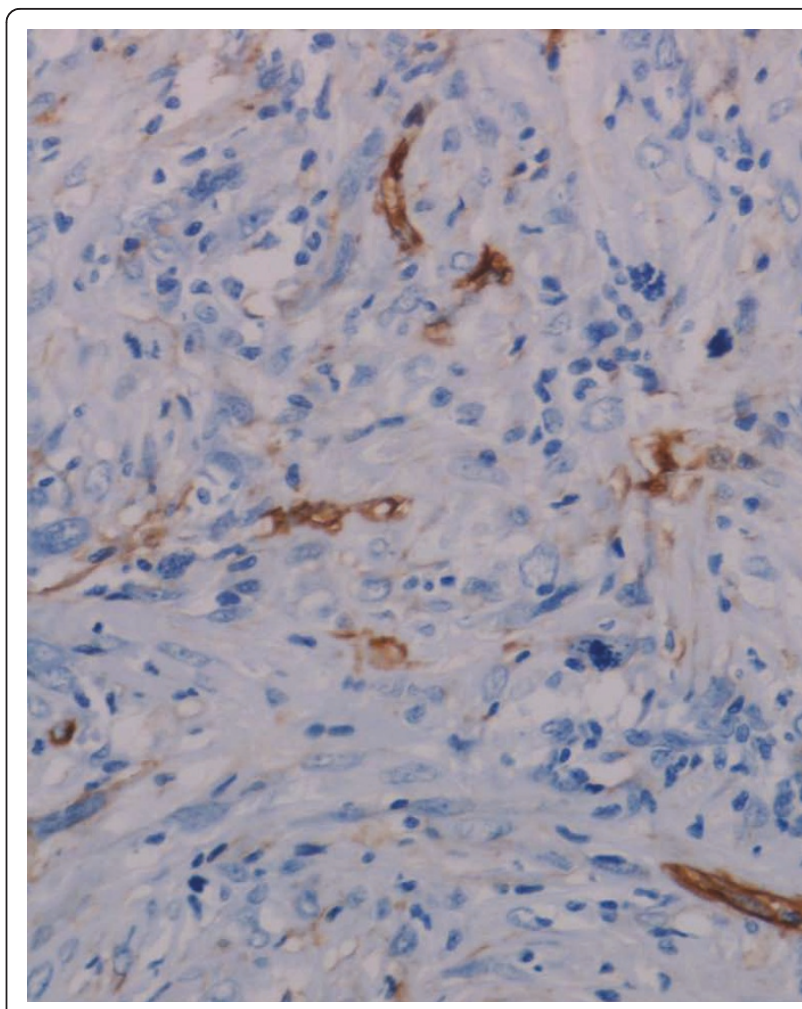

Figure 3 Intratumoural lymphatic vessels in a primary leiomyosarcoma, showing podoplanin expression by lymphatic endothelial cells.

Table 2 Patients with local recurrence following primary excision

\begin{tabular}{|c|c|c|c|c|c|c|c|c|c|}
\hline Age & Sex & Site & Max Diam eter $(\mathrm{cm})$ & Grade & $\begin{array}{l}\text { MSTS } \\
\text { Stage }\end{array}$ & $\begin{array}{l}\text { Time to first } \\
\text { recurrenc e } \\
\text { (Months) }\end{array}$ & Number of recurrences & Margins & Adjuvant Radio therapy \\
\hline 55 & $\mathrm{~F}$ & Arm & 5 & 3 & $2 b$ & 3 & 2 & Clear & Yes \\
\hline 77 & $\mathrm{~F}$ & Calf & Unknown & 2 & $2 b$ & 24 & 2 & Clear & Yes \\
\hline 77 & M & Buttock & 8 & 3 & $2 b$ & 3 & 4 & Clear & Yes \\
\hline 67 & $\mathrm{~F}$ & Thigh & 13 & 3 & $2 b$ & 9 & 2 & Clear & Yes \\
\hline 67 & M & Buttock & 12 & 2 & $2 b$ & 4 & 2 & Clear & Yes \\
\hline 55 & $\mathrm{~F}$ & Calf & 9 & 3 & $2 b$ & 5 & 1 & Marginal & Yes \\
\hline 76 & M & Forearm & unknown & 2 & $2 b$ & 19 & 1 & Clear & Yes \\
\hline
\end{tabular}

Table 3 Patients with lymph node metastasis

\begin{tabular}{|c|c|c|c|c|c|c|c|c|}
\hline Age & Sex & Site & $\begin{array}{l}\text { Max Diameter } \\
(\mathrm{cm})\end{array}$ & Grade & MSTS Stage & Margins & Aduvant Radiotherapy & $\begin{array}{l}\text { Time to detection of lymph node metastasis } \\
\text { (months) }\end{array}$ \\
\hline 79 & $\mathrm{~F}$ & Thigh & 8.5 & 3 & $2 b$ & Clear & Yes & 21 \\
\hline 53 & M & Thigh & 8 & 3 & $2 b$ & Clear & No & 3 \\
\hline
\end{tabular}


sites. The findings of the present study indicate that deep soft tissue leiomyosarcoma of the extremities, in contrast to leiomyosarcoma arising at other sites has a greater propensity to local recurrence. Such recurrences are difficult to treat and surgical resection of an already irradiated area remains the only option.

\section{Conclusion}

This study has shown that patients with leiomyosarcoma of deep soft tissues of the extremities have a rate of lymph node metastasis of $7 \%$ and a local recurrence rate of $25.9 \%$ despite adequate excision and post-operative radiotherapy. On the basis of this study, we do not advocate the use of SLNB to this group of patients except in cases where lymphatics can be demonstrated in the primary tumour. Our findings emphasise the importance of close follow up, especially for high grade leiomyosarcomas, particularly in the first year post surgery, as there is a high incidence of local recurrence.

\section{Authors' contributions}

$H G, P C, M G$ and DW contributed to the design of the study. $H G, M G$ and $P C$ conducted the study. NA carried out pathological studies and MIL, HPG, MG and NA wrote the paper. All authors have read and approved the final manuscript.

\section{Competing interests}

The authors declare that they have no competing interests.

Received: 11 February 2011 Accepted: 1 August 2011

Published: 1 August 2011

\section{References}

1. Evans HL, Shipley J: Leiomyosarcoma. In Pathology and genetics of tumours of soft tissue and bone. Edited by: Fletcher DCM, Unni KK, Mertens F. Lyon, IARC Press; 2002:131-134.

2. Weiss SW, Goldblum JR: Leiomyosarcoma. Enzinger and Weiss's Soft Tissue Tumours. 5 edition. St. Louis Mosby; 2008, 545-564.

3. Hashimoto H, Daimaru Y, Tsuneyoshi M, Enjoji M: Leiomyosarcoma of the external soft tissue. Cancer 1986, 57:2077-2088.

4. Sondak VK, Chang AE: Clinical evaluation and treatment of soft tissue sarcomas. In Enzinger and Weiss's soft tissue tumours. Fourth edition. Edited by: Weiss SW, Goldblum JR. St Louis Mosby; 2001:21-44.

5. Fong $Y$, Coit DG, Woodruff JM, et al: Lymph node metastasis from soft tissue sarcoma in Adults: Analysis of data from a prospective database of 1772 sarcoma patients. Ann Surg 1993, 217:72-77.

6. Behranwala KA, A'Hern $\mathrm{R}$, Al-Muderis $\mathrm{O}$, et al: Prognosis of lymph node metastasis in soft tissue sarcoma. Ann Surgical Oncol 2004, 11:714-719.

7. Gow KW, Rapkin LB, Olson TA, et al: Sentinel lymph node biopsy in the pediatric population. J Pediatr Surg 2008, 43:2193-8.

8. Kayton ML, Delgado R, busam K, et al: Experience with 31 sentinel lymph node biopsies for sarcomas and carcinomas in pediatric patients. Cancer 2008, 1;112:2052-9.

9. Maduekwe UN, Hornicek FJ, Springfield DS, et al: Role of sentinel lymph node biopsy in the staging of synovial, epithelioid, and clear cell sarcomas. Ann Surg Oncol 2009, 16:1356063.

10. $10 \mathrm{DN}$, Weingrad DN, Rosenberg SA: Early lymphatic spread of osteogenic and soft-tissue sarcomas. Surgery 1978, 84:231-240.

11. Mazeron JJ, Suit HD: Lymph nodes as sites of metastasis from sarcomas of soft tissue. Cancer 1987, 60:1800-1808.

12. Mahendra G, Kliskey $\mathrm{K}$, et al: Intratumoural lymphatics in benign and malignant soft tissue tumours. Virchows Archiv Pathol Anat 2008, 453:457-464
13. Blazer DG, Sabel MS, Sondak VK: Is there a role for sentinel lymph node biopsy in the management of sarcoma? Surg Oncol 2003, 12:201-206.

14. Morton DL, Cochran AJ, Thompson JF: The rational for sentinel-node biopsy in melanoma. Nat Clin Pract Oncol 2008, 5:510-511.

15. McMasters KM, Reintgen DS, Ross Ml, et al: Sentinel lymph node biopsy for melanoma: Controversy despite widespread agreement. J Clin Oncol 2001, 19:2851-2855.

16. Puleo CA, Messina JL, Riker Al, et al: Sentinel node biopsy for thin melanomas: Which patients should be considered. Cancer Control 2005, 12:230-235.

17. Balch CM, Soong SJ, Gershenwald JE, et al: Prognostic factors analysis of 17,6000 melanoma patients: validation of the American Joint Committee on Cancer melanoma staging system. J Clin Oncol 2001, 19:3622-3634.

18. Balch CM, Buzzaid AC, Atkins MB, et al: A new American Joint Committee on Cancer staging system for cutaneous melanoma. Cancer 2000, 88:1484-1491.

19. Mankin HJ, Hornicek FJ: Diagnosis, classification, and management of soft tissue sarcoma. Cancer Control 2005, 12:5-21.

doi:10.1186/2045-3329-1-7

Cite this article as: Lamyman et al.: Local recurrence and assessment of sentinel lymph node biopsy in deep soft tissue leiomyosarcoma of the extremities. Clinical Sarcoma Research 2011 1:7.

\section{Submit your next manuscript to BioMed Central and take full advantage of:}

- Convenient online submission

- Thorough peer review

- No space constraints or color figure charges

- Immediate publication on acceptance

- Inclusion in PubMed, CAS, Scopus and Google Scholar

- Research which is freely available for redistribution 